\title{
La vivienda como objeto de estudio desde el derecho: la vivienda como derecho humano y la cátedra UNESCO sobre vivienda
}

\author{
Housing as an object of study from the right: housing as a human \\ right and the UNESCO Chair on housing
}

\author{
Ángeles Galiana Saura* \\ Fecha de recepción: 28-04-2017 - Fecha de aceptación: 09-07-2017 \\ Hábitat y Sociedad (ISSN 2173-125X), n. ${ }^{\circ}$ 10, noviembre de 2017, pp. 129-144. \\ http://dx.doi.org/10.12795/HabitatySociedad.2017.i10.08
}

\section{Summary}

The existence of a fundamental right to housing is the basis for its full legal enforceability, and therefore also for its full guarantee and satisfaction beyond its consideration as a basic need (of the most important) of the subject. Only through the formal recognition of a fundamental right to housing can we demand an adequate legislative development in terms of equality and direct judicial action in case of its violation or non-satisfaction. With respect to housing research, there are two major challenges facing the jurist: the first is the close relationship between housing and the socio-economic and political reality of the context in question; and the second challenge or difficulty is non-uniformity in doctrine and legislation regarding the consideration of housing as a fundamental subjective right. Finally, it is briefly stated how this research is being carried out within the framework of the UNESCO Chair of Housing of the Rovira i Virgili University.

\section{Key words}

Housing, Subjective right to housing, Right to the city, Fundamental right to housing, Housing research

\section{Resumen}

La existencia de un derecho fundamental a la vivienda es la base para su plena exigibilidad jurídica y, por lo tanto, también para su plena garantía y satisfacción, más allá de su consideración como una necesidad básica (de las más importantes) del individuo. Solo a través del reconocimiento formal de un derecho fundamental a la vivienda podemos exigir un adecuado desarrollo legislativo en términos de igualdad y una acción judicial directa en caso de su vulneración o no satisfacción. Respecto a la investigación en materia de vivienda existen dos grandes retos a los que el jurista ha de enfrentarse: el primero es la estrecha relación que tiene la vivienda con la realidad socioeconómica y política del contexto en el que se trate; y el segundo reto o dificultad es la no uniformidad en la doctrina y en la legislación respecto a la consideración de la vivienda como un derecho subjetivo fundamental. Finalmente, se indica brevemente cómo se está efectuando esta investigación en el marco de la cátedra UNESCO de vivienda de la Universidad Rovira i Virgili.

\section{Pallabras clave}

Vivienda; Derecho subjetivo a la vivienda; Derecho a la ciudad; Derecho fundamental a la vivienda; Investigación sobre vivienda

\footnotetext{
* Profesora contratada doctora de Filosofía del Derecho, investigadora de la cátedra UNESCO de Vivienda. Universidad Rovira i Virgili (Tarragona).
} 


\section{Introducción ${ }^{1}$}

La burbuja inmobiliaria y la crisis hipotecaria han sido determinantes para poner sobre la mesa que la vivienda ha sido tradicionalmente considerada como un activo financiero y no tanto como un derecho humano. ${ }^{2}$ Ello comporta la necesidad de un cambio de perspectiva y la necesidad de retomar con fuerza la reivindicación de la vivienda como un derecho subjetivo.

De ahí que creo que uno de los grandes retos para la investigación sobre vivienda que aún hay que plantear es la necesidad de un reconocimiento formal de la vivienda como derecho subjetivo fundamental, más allá de los reconocimientos parciales que de facto se han ido realizando, en parte por la jurisprudencia y en parte por la legislación (en nuestro país de forma tímida la Ley Vasca 13/2015, de 18 de junio, de vivienda reconoce un derecho subjetivo a la ocupación legal de la vivienda en su artículo 6).

La existencia de un derecho fundamental a la vivienda es la base para su plena exigibilidad jurídica y, por lo tanto, también para su plena garantía y satisfacción, más allá de su consideración como una necesidad básica (de las más importantes) del individuo. Solo a través del reconocimiento formal de un derecho fundamental a la vivienda podemos exigir un adecuado desarrollo legislativo en términos de igualdad y una acción judicial directa en caso de su vulneración o no satisfacción.

Sin embargo, cabe anotar que, cuando pretendemos entrar en el estudio de la vivienda desde el punto de vista jurídico, nos encontramos ante primer un gran reto a afrontar, y es el de su estrecha relación con la realidad socioeconómica y política del momento, al que cabe sumar su discutida consideración como derecho subjetivo. Ello conlleva la necesidad de abarcar diferentes aspectos previos que son fundamentales para comprender la problemática a abordar que van más allá de los aspectos relacionados con la configuración de la vivienda como un derecho de los ciudadanos, tales como la consideración de la vivienda como un activo económico, su relación, por tanto, con el mercado inmobiliario, su encuadre dentro del régimen urbanístico, su afectación social, etc.

De ahí que, cuando se pretende analizar la problemática que plantea la vivienda y contribuir a proponer soluciones para elaborar adecuadas políticas de vivienda que hagan efectivo el derecho a una vivienda digna y adecuada para la persona y su familia que pregona el artículo 25 de la Declaración Universal de Derechos Humanos (entre otras normas de carácter internacional), se deba partir de la consideración de cuatro grandes dimensiones, conectadas entre sí, que han de ser tenidas presentes para elaborar adecuadas (efectivas) políticas de vivienda, y que son las dimensiones política, social, económica y ambiental.

Como acabo de indicar, la vivienda está estrechamente relacionada con la realidad económica y financiera del contexto en el que se analiza. Por un lado, tradicionalmente la vivienda ha sido considerada como un pilar importante del desarrollo económico de un país, pues impulsaba la actividad del sector de la construcción como elemento generador de empleo, a la vez que un activo económico o financiero (a nivel personal quizás el más importante). No obstante, y tras la manifestación más pronunciada de la aún vigente crisis económica (aproximadamente desde el año 2007), ${ }^{3}$ los planes de vivienda posteriores 
hacían y hacen mención a la necesidad de la rehabilitación del parque inmobiliario existente y a medidas de fomento del alquiler, así como a la regeneración y renovación urbanas. ${ }^{4} \mathrm{Y}$, por otro lado, no cabe olvidar que al tratarse de un derecho social o prestacional, para hacerse efectivo, depende de los recursos económicos y financieros de los que dispone el país.

La segunda dimensión a tener presente es la ambiental: la vivienda es un elemento fundamental del entorno urbano que debe ser respetuosa con el medioambiente (de ahí que se incentive en las últimas políticas de vivienda la rehabilitación del parque inmobiliario, o que incentiven medidas de eficiencia energética, entre otras); y también la vivienda en el entorno rural y natural debe ser respetuosa con los espacios protegidos, garantizando la sostenibilidad ambiental. Por lo tanto, un elemento fundamental a tener presente es, como se remarcó en la Conferencia de Naciones Unidas Hábitat III celebrada en Quito en octubre de 2016, el desarrollo urbano sostenible y la afectación en el derecho a la vivienda de los efectos del cambio climático (como puede ser la pérdida de la vivienda a consecuencia de desastres naturales, por ejemplo).

Hemos de partir de que la vivienda no solo es una necesidad básica de los seres humanos (quizá de las más importantes, pues de ella depende incluso la propia supervivencia de la persona), sino que es un bien de un elevado coste económico (no cabe obviar en este sentido que la vivienda constituye uno de los mayores activos económicos que poseen las personas) y que es un elemento fundamental del entorno urbano (de ahí su estrecha relación con la planificación urbanística) y, por tanto, de la construcción de la ciudad. En este sentido, además, en el desarrollo de la política urbanística y de rehabilitación de viviendas tiene una afectación al medioambiente (la protección de espacios protegidos, promover un desarrollo urbano sostenible, sostenibilidad ambiental, etc.).

Desde el punto de vista de la dimensión social, cabe remarcar que la vivienda es un pilar indispensable para el desarrollo de la vida de la persona en sociedad. De hecho, se afirma que la vivienda delata y habla de las personas que la ocupan, teniendo en cuenta el valor intangible en términos de prestigio y desprestigio, según el lugar en que se ubique (Cabrera, 2005, p. 5). Tampoco cabe olvidar, también desde esta dimensión social, el importante problema de la falta de vivienda para importantes sectores de la población, que provoca un importante problema de exclusión social (Villalibre Fernández, 2011, pp. 12-19). Y no solo la no satisfacción del derecho da lugar a la exclusión social, ya que no se trata solamente de proteger a los "sin techo", sino también a colectivos vulnerables y garantizando la no discriminación, prestando especial atención a las personas que habitan en condiciones precarias, insalubres o en las periferias urbanas sin acceso a suministros, servicios, etc.

En síntesis, la vivienda es un elemento fundamental a considerar en la toma de decisiones, por lo tanto en la dimensión política, y no solo en las políticas públicas de vivienda, sino también de ordenación del territorio, ambientales, de vivienda sostenible y de eficiencia energética entre otras. ${ }^{5}$ En este sentido, la vivienda necesita de una política adecuada para hacerla efectiva, una política de vivienda global que abarque todas estas dimensiones, y también necesita que en la toma de decisiones puedan participar los interesados.

Como he indicado anteriormente, la Conferencia de Naciones Uni-
4 Tanto el Plan de Vivienda aprobado por Real Decreto 2066/2008, de 12 de diciembre de 2008, Plan de Vivienda y Rehabilitación 2009-2012, como el vigente actualmente aprobado por el Real Decreto $233 / 2013$, de 5 de abril, por el que se regula el Plan Estatal de fomento del alquiler de viviendas, la rehabilitación edificatoria, y la regeneración y renovación urbanas, 2013-2016, lo cual supone un cambio de política más acorde con otros países europeos.

5 Respecto a la dimensión ambiental, supone entender la vivienda en su ubicación y su relación con el medioambiente y el entorno urbano, y por lo tanto su implicación con la ordenación del territorio, el urbanismo y el sistema medioambiental (Martín Mateo, 1991, pp. 277 y ss.). 
das Hábitat III se centra en la conexión entre vivienda y desarrollo urbano sostenible y en la implementación de una nueva Agenda Urbana ${ }^{6}$ que haga hincapié en los efectos adversos del cambio climático para el goce efectivo de los derechos humanos, entre ellos el derecho a la vivienda adecuada como componente del derecho a un nivel de vida adecuado, además del derecho a la no discriminación en este contexto, pues la vivienda adecuada no es efectiva para millones de personas que siguen habitando en viviendas precarias y millones más sin hogar, con especial protección de colectivos de especial vulnerabilidad que pueden resultar discriminadas en el ejercicio del derecho (personas con discapacidad, ancianos, niños y mujeres). En este contexto se hace también hincapié en la necesidad de garantizar un elevado grado de seguridad en la tenencia que garantice una protección legal contra el desalojo forzoso, el hostigamiento y otras amenazas, así como la necesidad de promover, proteger y fortalecer diversas formas de tenencia de la vivienda, en particular por la necesidad de incorporar los derechos humanos en las políticas nacionales de urbanización y desarrollo rural y planificación, políticas de administración y gestión de la tierra que garantice la integración social con plena participación de todos los interesados, así como garantizar un recurso efectivo para el ejercicio del derecho de acceso a la justicia para todas las violaciones que se puedan efectuar en el contexto de la realización del derecho a la vivienda adecuada, retos todos ellos que se deben afrontar en el futuro más inmediato si queremos plantear una adecuada protección del derecho a la vivienda, retos que incluso van más allá de la vivienda y que podrían integrarse en una estrategia de protección de carácter más global que tendría lugar en el marco de un posible "derecho a la ciudad".

De hecho, podemos afirmar que las cuatro grandes dimensiones apuntadas pueden unificarse y convergen en este contexto más amplio que supone el derecho a la ciudad, dentro del cual encajaría el derecho a la vivienda, y que incluso se vaya reclamando incluso la posible reconversión del derecho a la vivienda en este derecho a la ciudad. ${ }^{7}$

6 El 20 de octubre de 2016 la Conferencia de Naciones Unidas sobre Vivienda y Desarrollo Sostenible - Hábitat III- adoptó en Quito la "Nueva Agenda Urbana", un documento conciso, con visión de futuro y orientado a la acción, que establece objetivos globales para el desarrollo urbano sostenible, reconsiderando la manera de construir, gestionar y vivir las ciudades, con la colaboración de todos los agentes interesados, partes implicadas y actores urbanos, tanto a nivel gubernamental como del sector privado. Puede consultarse en: http:/ / www.fomento.gob.es/NR/ rdonlyres/30F3327E-D773-4BD9-885EE59F3F178AFE/140024/20161020_Nueva_AgUrbadoptada.pdf.

7 Tanto el Foro Social de las Américas celebrado en Quito en el año 2004, como el Foro Urbano Mundial de Barcelona del mismo año, reivindicaron una "Carta mundial del derecho a la ciudad”, que incluye una gestión democrática de la ciudad (artículo II.1) y que contiene un capítulo referido al "derecho a la vivienda" (artículo XIV).

\section{El derecho a la ciudad como derecho "emergente"}

Se afirma que, si bien el derecho a la vivienda contempla esencialmente el derecho a habitar, un hecho social, y ello implica el derecho a vivir en un lugar donde la dignidad no se vea mermada por el entorno, este cobra su auténtico sentido en un ámbito mayor, en la ciudad. La ciudad es la manera del ser humano de estar en el mundo y por ello el derecho a la vivienda implica, en sentido amplio, el derecho a la ciudad, pues para que exista uno es necesario también la existencia del otro. Derecho a la ciudad que incorpora no solo espacio (ordenación territorial), sino también ciudadanía, participación, seguridad, bienestar o pertenencia, cuestiones que van estrechamente conectadas con la vivienda. La ciudad es el espacio de construcción de la ciudadanía y el espacio público es el elemento de sociabilidad y de conflicto que puede dar lugar a las desigualdades, pues el desarrollo de las ciudades puede ser el espacio para desigualdades crecientes, tanto sociales como políticas, económicas y ecológicas. La vivienda, como elemento vertebrador esencial de la ciudad y ámbito de desarrollo personal, es el primer paso para dar lugar a este derecho emergente a la ciudad.

La noción "derecho a la ciudad" suele atribuirse a la obra de Henri Lefebvre, que empleó para criticar el urbanismo practicado en los años se- 
tenta del pasado siglo, utilizando el término como un derecho a la "vida urbana, a la centralidad renovada, a los lugares de encuentros y cambios, a los ritmos de vida y empleos del tiempo que permiten el uso pleno y entero de estos momento y lugares" (Lefebvre, 1969, pp. 167-168). A partir de Lefebvre, desde diferentes ámbitos ha crecido la visibilidad y el interés por esta noción, esencialmente por David Harvey, quien renovando la idea de Lefebvre reafirma el derecho a la ciudad que no se limita al acceso al equipamiento urbano, sino que comprende un derecho a la vivienda, al trabajo, al tiempo y a producir colectivamente ciudad, de forma tal que atienda las necesidades de la gente. Según Jean-François Tribillon el derecho a la ciudad consiste en gozar de una vivienda adecuada, tener un trabajo remunerado, crear una familia, vivir a salvo de molestias policiales incluso cuando uno proviene de lejos. Pero también, simplemente y más específicamente, vivir en una ciudad bonita, cómoda, sana, respetuosa con el medioambiente (Tribillon, 2003).

El derecho a la ciudad no es una propuesta nueva, a pesar de que aún sigue configurándose como un derecho "emergente" debido a su falta de reconocimiento jurídico completo. Tal y como se ha indicado, hace ya casi 50 años que se popularizó y difundió a través de la obra de Lefebvre, para instaurar la posibilidad del "buen vivir" para todos y hacer de la ciudad un encuentro para la construcción de la vida colectiva. El derecho a la ciudad es la posibilidad de construir una ciudad en la que se pueda vivir dignamente, reconocerse como parte de ella, y donde se posibilite la distribución equitativa de diferentes tipos de recursos: trabajo, salud, educación, vivienda y recursos simbólicos, como memoria, participación y acceso a la información (Sugranyes, 2010, p. 75), en los derechos humanos y especialmente en los derechos económicos, sociales y culturales. En este sentido, el derecho a la ciudad no debería ser un derecho más, se trataría del

derecho a hacer cumplir los derechos ya formalmente suscritos por los Estados en tratados internacionales e instrumentalizados en el marco legal y normativo de los países. Por eso el derecho a la ciudad se basa en una dinámica de procesos y de conquistas, en las cuales los movimientos sociales son el motor garante de su cumplimiento (Sugranyes, 2010, p. 75).

Un paso fundamental en la construcción del derecho a la ciudad ha sido la elaboración de la Carta Mundial por el Derecho a la Ciudad articulada por Habitat International Coalition (HIC),${ }^{8}$ que busca recoger los compromisos y medidas que deben ser asumidos por la sociedad civil, los gobiernos locales y nacionales, parlamentarios y organismos internacionales para que todas las personas vivan con dignidad en las ciudades. ${ }^{9}$

Según la Carta Mundial del Derecho a la Ciudad, este nuevo derecho es un derecho colectivo de los habitantes de las urbes, basado en sus usos y costumbres, en especial de los grupos vulnerables y desfavorecidos, para que se les confiera legitimidad de acción y de organización hacia la libre autodeterminación y un nivel de vida adecuado. ${ }^{10} \mathrm{La}$ Carta basa su propuesta en tres ejes básicos: 1) el ejercicio pleno de la ciudadanía, es decir, el ejercicio de todos los derechos humanos, que aseguran el bienestar colectivo de los habitantes y que promueven la producción y gestión social del hábitat; 2) la gestión democrática de la ciudad, a través de la participación de la sociedad de forma directa y activa en el planeamiento y gobierno de las ciudades, fortaleciendo las administraciones públicas a escala local, así como las organizaciones
8 Que puede consultarse en: http:// www.ugr.es/ revpaz/documentacion/ rpc_n5_2012_doc1.pdf.

9 De forma paralela, algunos gobiernos, tanto a nivel regional, como nacional y local, han venido generando instrumentos jurídicos en pro del reconocimiento del derecho a la ciudad. Destacan, a nivel internacional, la Carta Europea de Salvaguarda de los Derechos Humanos en la Ciudad y el Estatuto de la Ciudad de Brasil de 2001; y, a nivel local, la Carta de Montreal y la Carta de la Ciudad de México por el derecho a la ciudad. Cabe destacar también la inclusión del derecho a la ciudad en algunas Constituciones como la de Ecuador y la de Bolivia.

10 Tal y como indica Sugranyes, se realiza el derecho a la ciudad cuando hay: ejercicio pleno de la ciudadanía y gestión democrática de la ciudad; función social de la ciudad y de la propiedad urbana; igualdad, no discriminación; protección especial de grupos y personas en situación de vulnerabilidad; compromiso social del sector privado; impulso de la economía solidaria y políticas impositivas progresivas; planificación y gestión social de la ciudad; producción social del hábitat; desarrollo urbano equitativo y sustentable; derecho a la información pública; libertad e integridad; participación política; derecho a la justicia; derecho a la seguridad pública y a la convivencia pacífica, solidaria y multicultural; derecho al agua, al acceso y suministro de servicios públicos domiciliarios y urbanos; derecho al transporte público y la movilidad urbana; derecho a la vivienda; derecho al trabajo; derecho a un medioambiente sano y sostenible (Sugranyes, 2010, p. 77). 
sociales; y 3) la función social de la propiedad y de la ciudad, donde predomine el bien común sobre el derecho individual de propiedad, lo que implica el uso socialmente justo y ambientalmente sustentable del espacio urbano (Sugranyes, 2010, p. 77).

El derecho a la ciudad contiene muchos derechos, lo que lo vuelve muy difícil de exigir e implementar. Para conquistar el derecho a la ciudad es necesario primero difundir el concepto y la propuesta de cambio, articular los procesos de movilización social e incidir en la formulación de políticas públicas. Este proceso se ha desarrollado de manera amplia en varios países de América latina, sobre todo en Brasil, México y Ecuador. El alcance de este desafío implica cambios estructurales profundos en los patrones de producción, consumo y en las formas de apropiación del territorio y de los recursos naturales. El derecho a la ciudad se refiere a la "búsqueda de soluciones contra los efectos negativos de la globalización, la privatización, la escasez de los recursos naturales, el aumento de la pobreza mundial, la fragilidad ambiental y sus consecuencias para la supervivencia de la humanidad y del planeta". ${ }^{11}$

Debido a esta dificultad para poder hacer realidad este derecho emergente a la ciudad, consideramos que un paso previo ha de ser la delimitación de la vivienda — como elemento vertebrador de la ciudad, tal y como se ha indicado anteriormente- como derecho subjetivo y como derecho fundamental, lo que forma parte de mi investigación.

\section{La vivienda como derecho subjetivo}

En este apartado intentaré abordar una aproximación a la problemática de la vivienda en su consideración actual vinculada a su garantía y protección como derecho subjetivo de carácter social y como derecho fundamental, partiendo de la premisa de que si se pretende hacer efectivo el derecho a una vivienda digna hemos de proceder previamente a su reconocimiento formal como derecho subjetivo (en primer lugar) y como derecho fundamental para, a partir de aquí, proceder a su tutela jurídica efectiva a través de las vías previstas para la protección de este tipo de derechos, sin necesidad de un desarrollo legislativo posterior.

Todo este planteamiento cabe recordar que se encuadra en un contexto aún de crisis que reclama socialmente la necesidad de un alojamiento digno y teniendo presente que, si bien las políticas públicas de vivienda tradicionalmente se han articulado sobre la vivienda "protegida" o "social", en los últimos años y debido a las carencias de viviendas "dignas" también se han ido orientando hacia la rehabilitación de las viviendas ya existentes, así como hacia la reforma del mercado de alquileres y otras formas de tenencia de la vivienda. Sin embargo, cabe ya apuntar que todo ello se ha realizado sin contar con unos criterios mínimos de técnica legislativa coherentes y sin una política de vivienda global que trate todos estos aspectos.

De hecho, para concretar una adecuada política de vivienda habría que partir de la consideración de la vivienda como un derecho subjetivo, incluso como un derecho fundamental, además del estudio del contenido propio del derecho protegido, de la significación del adjetivo "adecuada" o "digna" que acompaña a la vivienda, siendo una necesidad básica del individuo.

El reconocimiento de la vivienda como derecho viene establecido a nivel internacional de manera clara como parte del contenido del derecho subjetivo a un "nivel de vida adecuado", esencialmente en la De-

11 Cfr. Hábitat International CoalitionAmérica latina (HIC-AL). El Derecho a la Ciudad y la Carta Mundial por el Derecho a la Ciudad (2006). Recuperado el 17 de enero de 2017 de: http://www.hic-al.org/ proyectos/derechoalavivienda/desc/derechociudad2.html. 
claración Universal de Derechos Humanos (artículo 25), que proclama que "toda persona tiene derecho a un nivel de vida adecuado que le asegure, así como a su familia, la salud y el bienestar, y en especial la alimentación, el vestido, la vivienda, la asistencia médica...”, y en el Pacto Internacional de Derechos Económicos, Sociales y Culturales (artículo 11, párrafo 1) que determina que

los Estados Partes en el presente Pacto reconocen el derecho de toda persona a un nivel de vida adecuado para sí y su familia, incluso alimentación, vestido y vivienda adecuados, y a una mejora continua de las condiciones de existencia. Los Estados Partes tomarán medidas apropiadas para asegurar la efectividad de este derecho...

En este caso, incluso recomienda a los Estados Partes a llevar a cabo medidas apropiadas para que el derecho a una vivienda adecuada desprenda toda su eficacia jurídica.

Asimismo, la Observación General número 4 del Comité de Derechos Económicos, Sociales y Culturales sobre el derecho a una vivienda adecuada determina y concreta las condiciones que configuran el carácter "adecuado" de la vivienda, desarrollando el contenido del artículo 11.1 del PIDESC. En este sentido, no solo determina que el derecho a la vivienda adecuada es para todos, interpretando la afirmación del PIDESC sobre "para sí y su familia”, pues no se puede imponer limitación alguna en relación al género, sino que el concepto de "familia" debe entenderse en sentido extenso, no literal de la palabra. Además, determina el objeto del derecho, pues el derecho a la vivienda no trata de tener un tejado o cobijo para la persona, sino que es derecho a vivir en seguridad, paz y dignidad en alguna parte, con lo cual en el concepto de vivienda "adecuada" hay que entender los siguientes elementos: seguridad jurídica de la tenencia (incluida una protección contra el desalojo); disponibilidad de servicios, materiales, facilidades e infraestructuras (incluido el acceso al agua potable y a servicios sanitarios); gastos soportables; habitabilidad (incluida la protección contra el frío, la humedad, el calor, la lluvia, el viento y las enfermedades); asequibilidad; lugar (un emplazamiento adecuado, alejado de fuentes de contaminación y próximo a servicios sanitarios y escolares) y adecuación cultural.

Sin embargo, y como señala también M.J. González Ordovás, a pesar del significativo reconocimiento jurídico que a nivel nacional e internacional se ha otorgado al derecho a la vivienda, es posible afirmar aún hoy en día que está entre nosotros débil y escasamente tutelado (González Ordovás, 2013, p. 46), lo cual choca con lo establecido en el artículo 30 de la Carta Social Europea Revisada, donde se señala que el derecho a la vivienda no solo proporciona un bien necesario en sí mismo, sino que de él depende la garantía del "ejercicio efectivo del derecho a protección contra la pobreza y la exclusión social”, y que obliga a los Estados Partes a

adoptar medidas en el marco de un planteamiento global y coordinado para promover el acceso efectivo, en particular al empleo, a la vivienda, a la formación, a la enseñanza, a la cultura y a la asistencia social y médica de las personas que se encuentre o corran el riesgo de encontrarse en una situación de exclusión social o de pobreza, así como de sus familias. ${ }^{12}$

Es clara la conexión de la vivienda con la protección y eficacia de los derechos civiles y políticos (derecho a la vida, honor, intimidad, parti-
12 Y aquí aparece también otro término fundamental a tener presente cuando intentamos construir el contenido del derecho subjetivo a la vivienda: la familia (Giuglia, 2011, pp. 555-556). 
cipación política...), además de presupuesto indispensable para la eficacia y garantía de otros derechos sociales, económicos y culturales (salud, educación, trabajo...), pero no cabe olvidar que esencialmente la falta de vivienda repercute de manera relevante también en la igualdad. Y aquí no me refiero al acceso a la vivienda en régimen de propiedad, sino que la necesidad de alojamiento se puede sostener con otros regímenes o tenencias de la vivienda. ${ }^{13}$

Tradicionalmente, y como es conocido, nuestra doctrina jurídica se ha postulado mayoritariamente por la no consideración en nuestro ordenamiento jurídico del derecho a la vivienda como un derecho subjetivo debido a su inclusión en nuestra Constitución en su artículo 47, apareciendo, pues, formalmente configurado como un principio rector de la política económica y social. Esto supone, como también es sabido, una imposición de deberes y mandatos o directrices dirigido a los poderes públicos que no supone, en principio, su exigencia por parte de los ciudadanos como derecho subjetivo (López Ramón, 2014).

Todo derecho subjetivo comporta un correlativo deber jurídico, y por lo tanto un sujeto obligado a hacer efectivo el derecho. En este sentido, existen reticencias aún en la configuración jurídica del derecho alegando su imposibilidad de hacerlo efectivo en sentido absoluto. Se trataría en todo caso de una obligación de medios, no de resultados, para que los poderes públicos reconozcan, respeten, protejan y promuevan cuantas medidas sean necesarias para garantizar una vivienda digna y adecuada.

Si se configura como derecho subjetivo deberíamos incluirlo en la subcategoría de derechos "sociales" ${ }^{14}$ de "prestación en sentido estricto”, según la categoría de R. Alexy (Alexy, 1993, pp. 189-194, 419 y ss.), derecho que el individuo ostenta frente al Estado para obtener algo que podría hacerlo también de particulares, si poseyera los medios financieros necesarios y si encontrase en el mercado una oferta suficiente. En este sentido, el derecho a la vivienda implicaría la exigencia de una acción por parte del Estado para su cumplimiento, a diferencia de otros derechos de libertad que requieren básicamente una actitud de abstención por parte del Estado.

La situación de crisis económica en la práctica totalidad de Europa ha supuesto un retroceso en el avance de la garantía de los derechos sociales, pero, como indica M.J. González Ordovás, al respecto cabría considerar al menos tres cuestiones: 1) que si bien es cierto que tales derechos tienen un elevado coste, también lo es que parte del mismo es atribuible a que "a falta de adecuados mecanismos de garantía, su satisfacción ha quedado confiada en los sistemas de welfare a una onerosa y compleja mediación política y burocrática que por sus enormes espacios de discrecionalidad constituye la fuente principal de despilfarros, costes y, sobre todo, ineficacia" (Ferrajoli, 1999, p. 110); 2) tampoco es barato el mantenimiento e implementación de los otros, los civiles y políticos, y a nadie se le ocurre limitarlos, condicionarlos o suprimirlos por razón de su carestía; y 3) además de conocer el coste que supone el desarrollo de los derechos sociales, habría también que analizar cuál es el coste de no hacerlo (González Ordovás, 2013, p. 40).

No obstante, y a pesar de la previa consideración anterior y de la posible discusión doctrinal sobre su configuración o no como derecho subjetivo - cuestión en la que entraremos con más detalle a continuación-, cierto es que no resulta discutible, tal y como también señala G. Pisarello, que el contenido del derecho a la vivienda aparece ligado a la dignidad de la persona y a su libre desarrollo (art. 10.1 CE) y también 
puede conectarse con los derechos a la integridad física y moral (art. $15 \mathrm{CE}$ ), a la intimidad (art. $18 \mathrm{CE}$ ) o a la libertad de residencia (art. $19 \mathrm{CE}$ ), así como a la no discriminación (igualdad formal y material, arts. 14 y $9.2 \mathrm{CE}$ ), a la salud (art. $45 \mathrm{CE}$ ) o a la educación (art. $27 \mathrm{CE}$ ), (Pisarello, 2009, pp. 4-5). Esta conexión entre el derecho a la vivienda y otros derechos sociales y civiles clásicos hace que el carácter "digno y adecuado" de la misma deba definirse a partir de su relación con el resto de derechos tutelados por el ordenamiento jurídico. De hecho, la interdependencia de los derechos humanos para Naciones Unidas no es nada novedoso, así como su indivisibilidad, pues el fundamento de los derechos es el mismo para todos: la dignidad de la persona, tanto se hable de derechos civiles y políticos como de derechos sociales, y el principio de indivisibilidad exige igual efectividad, pero ello no implica que las garantías hayan de ser idénticas. ${ }^{15}$

En este punto es cuando podemos cuestionarnos si en nuestro ordenamiento jurídico la vivienda está configurada como un derecho subjetivo a partir de su configuración jurídica en el artículo $47 \mathrm{CE}$, y aquí es donde, y como bien señala la profesora González Ordovás, las respuestas son de dos tipos (González Ordovás, 2013, p. 45): la que niega la propia consideración de la vivienda como derecho subjetivo; y la que considera que estamos ante un derecho subjetivo y dentro de la cual también cabe diferenciar entre la opinión de los que, por considerarlo un derecho de medios y no de resultados, le atribuyen ciertos rasgos característicos, ${ }^{16}$ de quienes lo entienden como un derecho subjetivo sin más, como Pisarello, para quien nada impide que los derechos sociales puedan considerarse derechos fundamentales, por mucho que esto supusiera un "cambio en la interpretación dominante" (Pisarello, 2009, p. 44).

La argumentación de parte de la doctrina más clásica sostiene que de ningún modo estamos ante un derecho subjetivo, incluso que ni siquiera estamos ante la presencia de un derecho, y se basa esencialmente en su ubicación sistemática en nuestro texto constitucional, fuera de cualquier pretensión de exigibilidad judicial directa, a partir de lo dispuesto por el artículo 53.3 CE, que marca las diferencias en el sistema de garantías de los derechos, distinguiendo entre derechos fundamentales y derechos que, pese a tener reconocimiento constitucional, no llegarían a serlo. Esta posición, no obstante, ha sido rechazada tanto por la doctrina como por la jurisprudencia en reiteradas ocasiones, ${ }^{17}$ pues no resulta tan discutible su consideración como derecho subjetivo como su consideración como derecho fundamental, cuestión que abordaremos más adelante.

Desde esta posición doctrinal de no consideración del derecho subjetivo a la vivienda se afirma también que no existe un derecho en sentido técnico si no hay un desarrollo legislativo del mismo, que no existe un derecho subjetivo sin acción. A medio camino entre ambas valoraciones está la opinión de quienes lo consideran un derecho "emergente", como Tejedor Bielsa, para quien "sin acción judicial [...] no hay derecho y no hay acción entendida como posibilidad de interponer una demanda para reclamar la declaración o defender un derecho sobre el derecho a la vivienda" (Tejedor Bielsa, 2010, p. 309). En contrapartida cabe apuntar que en algunas Comunidades Autónomas ya se ha derivado una acción del reconocimiento del derecho, como en Cataluña, Navarra o Euskadi.

Si bien la Constitución Española no lo configura expresamente como un derecho subjetivo, sí que ha sido la ley la que le otorga este
15 Respecto a la indivisibilidad e interdependencia de los derechos humanos vid. Anon (2015, pp. 193-197).

16 Como, por ejemplo, Ponce (2008, pp. 80 y ss.).

17 A modo de ejemplo, la sentencia del Tribunal Supremo de 18 de febrero de 2002 indicaba que "el párrafo primero del art. 47 de la CE [...] consagra un derecho social o de prestación que exige, consiguientemente, una intervención del Estado en la esfera social y económica y un hacer positivo de los poderes públicos para la consecución de la igualdad material que propugna el artículo 9.2 de la Constitución”. 
carácter. En concreto, esta configuración se hace expresa a partir de la Ley del Suelo 8/2007, donde en su artículo 4.a) indica que

todos los ciudadanos tienen derecho a: Disfrutar de una vivienda digna, adecuada y accesible, concebida con arreglo al principio de diseño para todas las personas, que constituya su domicilio libre de ruido u otras inmisiones contaminantes de cualquier tipo que superen los límites máximos admitidos por la legislación aplicable y en un medioambiente y un paisaje adecuados.

Otro de los argumentos de mayor peso en los que se basa esta posición clásica para rechazar la consideración de derecho subjetivo a la vivienda es su absoluta dependencia de los recursos económicos y financieros del país. No obstante, este argumento ha sido rebatido con la indicación de que otros derechos sociales se garantizan también con independencia de la coyuntura económica (sanidad o educación, por ejemplo) y que también los derechos de primera generación conllevan un coste económico para su garantía y no por ello se piensa en su restricción o no ejercicio en base a este argumento (solo cabe pensar en el elevado coste que supone el ejercicio del sufragio). Cabe tener presente que la configuración del derecho a la vivienda como derecho subjetivo no conllevaría una obligación de resultados, pues esto sería seguramente irrealizable, sino una obligación de medios, porque bajo el impulso del principio de eficacia del artículo 103 CE y al amparo de la relación sistemática los artículos 47 y $53.3 \mathrm{CE}$, los poderes públicos han de respetar, reconocer, proteger y promover cuantas medidas sean necesarias para hacer efectivo el mandato que la Constitución recoge en el artículo 47 y en virtud del cual tenemos derecho a una vivienda digna y adecuada (González Ordovás, 2013, pp. 70-71).

Finalmente, no cabe olvidar, como indica la profesora González Ordovás, que bajo todos los argumentos anteriormente esgrimidos a favor de su consideración como derecho subjetivo, existe un elemento unificador de los derechos, que se basa en la dignidad, que por ser única, hace que resulte absurdo pretender proteger bienes jurídicos como la intimidad, el libre desarrollo de la personalidad, la familia o la salud, por ejemplo, sin atender previamente a la necesidad de vivienda, requisito sine qua non para que aquellos puedan garantizarse (González Ordovás, 2013, p. 77).

\section{La vivienda como derecho fundamental}

Otra gran dificultad añadida en el análisis de la naturaleza jurídica de la vivienda es su posible configuración como un derecho fundamental, pues el mayor problema que plantea el derecho a la vivienda como derecho social prestacional es el de su eficacia, identificada como justiciabilidad. Justiciabilidad entendida como la posibilidad de reclamar la vulneración del derecho ante un juez o tribunal de justicia, elemento necesario para que el derecho sea reconocido de forma plena, pero no solo en términos de jurisdicción, sino también de garantías del derecho, de mecanismos de protección del mismo; garantías entendidas, según C. Courtis, como aquellos métodos, mecanismos o dispositivos que sirven para asegurar la efectividad de un derecho y con una tipología muy diversa: normativas, sociales, institucionales, especialmente de carácter público (Courtis, 2009, pp. 19-20). De ahí que se reclame tal 
consideración, para garantizar así, como también se indicó en la Conferencia de las Naciones Unidas de octubre de 2016 Hábitat III, un recurso efectivo para el ejercicio del derecho de acceso a la justicia para todas las violaciones que se puedan efectuar en el contexto de la realización del derecho a la vivienda adecuada.

Pero para alcanzar la plena eficacia del derecho a la vivienda en términos de justiciabilidad es necesario, insisto, su previo reconocimiento formal como derecho fundamental. Los derechos fundamentales constituyen el núcleo sustancial e indisponible de la democracia y el constitucionalismo y, desde esta perspectiva, en la medida que los derechos sociales son derechos fundamentales de su defensa depende también la defensa de la democracia, y aquí es donde debe encuadrarse el derecho a la vivienda, pues la vivienda es una condición previa para el pleno disfrute y eficacia de otros derechos humanos y/o fundamentales.

Y reafirmo esta cuestión porque en nuestro país aún existen dudas respecto a esta configuración jurídica desde el momento en que nuestra Constitución, como se ha explicado en el apartado anterior, sigue reconociendo a la vivienda en su artículo 47, apareciendo formalmente configurado como un principio rector de la política económica y social que conlleva una imposición de deberes y mandatos a los poderes públicos que no supone, en principio, su exigencia por parte de los ciudadanos como derecho subjetivo y se intenta alcanzar su garantía o eficacia por la vulneración de otros derechos fundamentales (derechos a la vida, a la intimidad, a la educación, etc.).

No obstante, a nivel regional e internacional se está avanzando en su configuración jurídica como derecho fundamental, pues así ha sido delimitada tanto por el Comité de Derechos Económicos, Sociales y Culturales, como por el Tribunal Europeo de Derechos Humanos, institución que ha protegido los derechos habitacionales a pesar de que el Convenio Europeo para la Protección de los Derechos Humanos y de las Libertades Fundamentales no incluye de manera explícita el derecho a la vivienda, pero han entrado, como recuerda G. Pisarello, por causa de su conexión con otros derechos civiles clásicos como el derecho a no ser sometido a tratos inhumanos o degradantes, derecho al debido proceso, derecho a la vida privada y familiar, derecho al domicilio o respeto a los bienes propios y a la propiedad (Pisarello, 2009).

También ha sido así reconocido por la jurisprudencia del Tribunal de Justicia de la Unión Europea: "En el Derecho de la Unión, el derecho a la vivienda es un derecho fundamental garantizado por el artículo 7 de la Carta que el tribunal remitente debe tomar en consideración al aplicar la Directiva 93/13", señalando, asimismo, que

el Tribunal Europeo de Derechos Humanos ha estimado que la pérdida de una vivienda es una de las más graves lesiones del derecho al respeto del domicilio y que toda persona que corra el riesgo de ser víctima de ella debe en principio poder obtener el examen de la proporcionalidad de dicha medida.

Estas afirmaciones, procedentes de la sentencia del Tribunal de Justicia de la Unión Europea de 10 de septiembre de 2014 (caso Kušionová), ${ }^{18}$ constituyen un innegable avance en el proceso de construcción de un derecho a la vivienda familiar justiciable, exigible ante los tribunales y determinante de una actitud proactiva de estos para lograr su efectiva protección. En este sentido, y por vez primera, el Tribunal de Justicia de la Unión Europea ha reconocido un derecho sub-
18 Sentencia que puede consultarse en: http://curia.europa.eu/juris/document/ document.jsf?text $=\&$ docid $=157486 \&$ pageI ndex $=0 \&$ doclang $=E S \&$ mode $=$ req \&dir $=\& 0$ cc=first\&part $=1 \& c i d=546634$. 
jetivo a la vivienda que va más allá de las Constituciones de los Estados Miembros que, cuando reconocen el derecho a la vivienda, regulan un principio de actuación o mandato a los poderes públicos para llevar a cabo políticas que garanticen este derecho.

La Unión Europea, siguiendo el camino planteado previamente por el Tribunal Europeo de Derechos Humanos, asume así planteamientos más avanzados que los vigentes en España donde, anclada aún la vivienda en los principios rectores de la política social y económica, parece resultar mucho más difícil impulsar su efectiva protección, aunque su protección especialmente a nivel internacional y europeo apunta a una prevalencia del derecho a la vivienda como condición previa para el pleno disfrute y eficacia de otros derechos humanos y/o fundamentales. En este sentido es posible afirmar que, afortunadamente, la Unión Europea ha asumido un planteamiento más avanzado. Su protección especialmente a nivel internacional y europeo apunta a una prevalencia del derecho a la vivienda como condición previa para el pleno disfrute y eficacia de otros derechos humanos y/o fundamentales, paso que debería darse también a nivel estatal.

\section{Sobre investigación y docencia en vivienda en la Universidad Rovira i Virgili: la cátedra UNESCO de vivienda ${ }^{19}$}

En el contexto de la Universidad Rovira i Virgili (Tarragona, España), se creó en el año 2014 la primera cátedra española de investigación sobre la vivienda con un carácter interdisciplinar e internacional, recogiendo una tradición de estudios en vivienda de diversos profesores desde hacía 20 años. A día de hoy, la componen 15 investigadores que organizan su aproximación al complejo fenómeno de la vivienda en cuatro pilares: la vivienda como derecho humano, el acceso a la vivienda, la gestión de la vivienda y su organización y la vivienda como activo financiero. En ellos caben tesis doctorales y trabajos relacionados con el derecho humano a la vivienda, la vivienda social y asequible, los alquileres, la mediación, las tenencias intermedias, la tributación de la vivienda o el mercado hipotecario, entre otros.

Sus investigadores procedemos de ámbitos disciplinares diferenciados, lo cual permite su estudio transversal, desde el derecho civil, el derecho internacional privado, el derecho procesal, el derecho financiero y tributario, el derecho romano y la filosofía del derecho, así como aportaciones y colaboraciones con la economía, la sociología o la antropología y el trabajo social.

Esta organización ha permitido a la cátedra el haber llevado a cabo hasta el momento 15 proyectos de investigación financiados tanto por entidades públicas como privadas, destacando los elaborados para la Comisión Europea y el Parlamento Europeo: el primero comparativo de los 28 sistemas de arrendamientos urbanos en la Unión Europea, un segundo sobre las barreras que tienen los extranjeros a la hora de adquirir inmuebles en un país comunitario y un tercero sobre desahucios y sinhogarismo.

La cátedra tiene como objetivo llevar su investigación hasta el final,

19 Dicha información está extraída de la publicación del director de la cátedra, el Dr. Sergio Nasarre Aznar, "Investigar sobre vivienda: de Tarragona a la UNESCO", publicado en Diari de Tarrago$n a$, el 25 de febrero de 2017. convertirla en docencia especializada para formar profesionales inmobiliarios y transferirla a la sociedad para que le sea realmente útil, lo cual debería ser una obligación para cualquier universidad pública. En cuanto a la docencia, la cátedra ha impulsado cuatro ediciones del 
posgrado de mediación y del posgrado de agente inmobiliario en la Fundación de la Universidad Rovira i Virgili. Por lo que respecta a la transferencia de la investigación, esta destaca por la participación de investigadores de la cátedra en el impulso y en la elaboración de cinco leyes sobre vivienda, cuatro de las cuales ya están aprobadas y en vigor: la Ley de Arrendamientos Urbanos de 2013, el Plan Estatal de Vivienda 2013-2016, la reforma del Código de Consumo de Cataluña para la protección de los consumidores hipotecarios y, especialmente, la ley que propicia un acceso asequible y sostenible a la vivienda en propiedad, a través de la propiedad compartida y de la propiedad temporal.

El reconocimiento internacional de la cátedra queda patente por su participación en el Comité de Coordinación de la European Network for Housing Research. Asimismo, la cátedra ha sido reconocida por la UNESCO como la sede única de la cátedra UNESCO de acceso a la vivienda en el mundo, en la cual se profundizará sobre la problemática de acceso y conservación de la vivienda, especialmente en población vulnerable.

\section{Función social de la investigación en vivienda de la cátedra UNESCO ${ }^{20}$}

La universidad pública, con vocación de servicio a la comunidad, ha de cumplir con una serie de funciones que pueden concentrarse en tres: docencia, investigación y transferencia (extensión), y actualmente podemos afirmar, sin duda, que el reto más importante que se puede afrontar es el de extrapolar los resultados de la investigación a la sociedad de forma efectiva, de tal manera que pueda valorarse y medirse el impacto que la investigación realizada tiene en su aplicación real en la sociedad a través de los beneficios que pueda conllevar (el denominado "impacto social" de la investigación). En este sentido no solo se trata de transferir el conocimiento o demostrar los resultados, sino de aportar un cambio, un beneficio que sea real y cuantificable. Es necesario, por lo tanto, que los resultados de la investigación lleguen a la sociedad y, tras su valoración, contribuyan a mejorarla.

Para la cátedra UNESCO de vivienda de la URV, alcanzar tal impacto social conforma uno de los pilares fundamentales de su actividad, junto a la investigación, la docencia y la transferencia de conocimientos. Su principal objetivo es facilitar el acceso a la vivienda y evitar su pérdida: reducir el número de desahucios, facilitar el acceso a las viviendas, evitar el sobreendeudamiento, democratizar la propiedad, comprender el sinhogarismo, mejorar el régimen de arrendamientos urbanos... son algunos ejemplos de los temas que están aún en la agenda de investigación.

Algunos ejemplos de las evidencias del impacto social que la cátedra UNESCO tiene en materia de vivienda son: la incorporación de las tenencias intermedias (la propiedad temporal y la propiedad compartida) en el Código Civil de Cataluña; la elaboración de un calculador del esfuerzo económico familiar, de manera que al introducir los ingresos económicos nos informa sobre cuál es la forma de tenencia (propiedad absoluta o tradicional, propiedad compartida, propiedad temporal y alquiler) que mejor se adecúa a las circunstancias de cada uno y evitar así su sobreendeudamiento; la colaboración con la elaboración de la Ley 20/2014, de protección de los consumidores hipotecarios; la participación en la elaboración del Plan Estatal de Vivienda (2013-2016); la
20 La información de este apartado es extraída del artículo de mi compañera investigadora de la cátedra Gemma Caballé Fabra sobre "La investigación en materia de vivienda más cerca de la Sociedad", publicada en Diari de Tarragona, el 26 de marzo de 2017. 
producción de un documental sobre desahucios y sinhogarismo (The Line) con propuestas de prevención y tratamiento de esta problemática; elaboración de unos principios para un nuevo régimen de alquileres para Cataluña, etc.

\section{Conclusiones}

La finalidad primordial de estas páginas era la de remarcar la necesidad de reclamar la consideración de la vivienda más allá de una necesidad básica del individuo a través de su garantía como derecho subjetivo fundamental y proceder a una investigación adecuada en estos términos. Para ello, en primer lugar, se ha analizado la naturaleza jurídica del derecho a la vivienda desde cuatro dimensiones o ámbitos (político, social, económico y ambiental) que se deben tener en consideración a la hora de elaborar políticas de vivienda que hagan efectivo el derecho. Estas cuatro dimensiones se unifican en el contexto de un derecho emergente aún más amplio que el de la vivienda, el derecho a la ciudad, que incorporaría además de los elementos de ordenación territorial, cuestiones de participación, inclusión, bienestar... que también deben formar parte del contenido a proteger en el derecho a la vivienda.

Asimismo, se ha apuntado que otra gran dificultad añadida en el análisis de la naturaleza jurídica de la vivienda es su posible configuración como un derecho fundamental, que determina su plena justiciabilidad. No obstante, se ha avanzado en los últimos años en la configuración jurídica de la vivienda como derecho fundamental, tanto a nivel internacional como regional y nacional, y así ha sido delimitada por el Comité de Derechos Económicos Sociales y Culturales, el Tribunal Europeo de Derechos Humanos, el Tribunal de Justicia de la Unión Europea y aún nos queda por enfrentarnos a su reconocimiento en nuestro país.

Por otra parte, he querido apuntar cómo se inserta esta investigación en el marco de un grupo de investigación más amplio, que trata sobre la problemática de la vivienda fundamentalmente en cuatro ámbitos (la vivienda como derecho humano, el acceso a la vivienda, la gestión de la vivienda y su organización y la vivienda como activo financiero), y que plantea su investigación con el objetivo de que sus resultados lleguen a la sociedad y, en la medida de lo posible, constituyan un beneficio para la misma y, por lo tanto, contribuyan a una sociedad mejor. 


\section{Referencias}

Abramovich, V. y Courtis, C. (2001). Los derechos humanos como derechos exigibles. Cuadernos Electrónicos de Filosofía del Derecho, 4.

- (2006). El umbral de la ciudadanía. El significado de los derechos sociales en el Estado social Constitucional. Buenos Aires: Editores del Puerto.

Alexy, R. (1993), Teoría de los derechos fundamentales. Madrid: Centro de Estudios Constitucionales.

Añón, M.J. (2015). Derechos humanos y principio de efectividad: claves interpretativas. En VV.AA., Revenga Sánchez, M. y Cuenca Gómez, P. (eds.), El tiempo de los derechos. Los derechos humanos en el siglo XXI. Madrid: Dykinson.

Caballé Fabra, G. (2017). La investigación en materia de vivienda más cerca de la Sociedad. Diari de Tarragona, 26 de marzo.

Cabrera, P.J. (2005). Vivienda y alojamiento. Documentación Social, 138.

Courtis, C. (2009). El mundo prometido. Escritos sobre derechos sociales y derechos humanos. México D.F: Fontamara.

Ferrajoli, L. (1999). Derechos y garantías. La ley del más débil. Traducción de P.A. Ibáñez y A. Greppi. Madrid: Trotta.

Giuglia, G. (2011). El derecho a la vivienda en la Carta Social Europea: a propósito de una reciente condena a Italia del Comité Europeo de derechos sociales. Revista de Derecho Político, 82.

González Ordovás, M.J. (2013). El derecho a la vivienda. Reflexiones en un contexto socioeconómico complejo. Madrid: Dykinson.

Habitat International Coalition-América Latina (HICAL) (2006). El Derecho a la Ciudad y la Carta Mundial por el Derecho a la Ciudad. Recuperado el 1 de mayo de 2017 de: http://www.hic-al.org/proyectos/derechoalavivienda/desc/derechociudad2.html.

Lefebvre, H. (1969). El derecho a la ciudad. Barcelona: Península.

López Ramón, F. (2014). El derecho subjetivo a la vivienda. Revista Española de Derecho Constitucional, 102.

Martín Mateo, R. (1991a). Tratado de Derecho Ambiental, Vol. I. Madrid: Trivium.

- (1991b). Elementos del Derecho ambiental. Sistema: Revista de Ciencias Sociales, 104-105.

Murie, A. (1988). Secure and contented citizens? Home ownership in Britain. En Marsh, A. y Mullins, D. (eds.), Housing and public policy: citizenship, choice and control. Oxford: Oxford University Press.

Nasarre Aznar, S. (2011). La insuficiencia de la normativa actual sobre el acceso a la vivienda en pro- piedad y en alquiler: la necesidad de instituciones jurídico-privadas alternativas para facilitar el acceso a la vivienda. Algunas propuestas. En VV.AA., Nasarre, S. (dir.) y Simón, H. (coord.), El acceso a la vivienda en un contexto de crisis. Madrid: Edisofer.

Nasarre Aznar, S. y Simón Moreno, H. (2103). Fraccionando el dominio público: las tenencias intermedias para facilitar el acceso a la vivienda. Revista Critica de Derecho Inmobiliario, 739.

Nasarre Aznar, S. y García Teruel, R.M. (2016). El acceso a la vivienda en España. Estudio jurídico ADICAE: vivienda y financiación.

Nasarre Aznar, S. (2107). Investigar sobre vivienda: de Tarragona a la UNESCO. Diari de Tarragona, 25 de febrero.

Pisarello, G. (2009a). El derecho a la vivienda como derecho social: implicaciones constitucionales. $R e^{-}$ vista catalana de Dret Públic, 38.

- (2009b). La justiciabilidad de los derechos sociales en el sistema constitucional español. En Pisarello, G., García Morales, A. y Olivas Díaz, A., (2009), Los derechos sociales como derechos justiciables: potencialidades y limites. Albacete: Editorial Bomarzo.

Ponce, J. (2008). El derecho a la vivienda. Nuevos desarrollos normativos y doctrinales y su reflejo en la ley catalana 18/2007, de 28 de diciembre, del derecho a la vivienda. En VV.AA., Ponce, J. y Sibina, S. (coords.), El derecho a la vivienda en el siglo XXI: sus relaciones con la ordenación del territorio y el urbanismo. Madrid: Marcial Pons.

Sugranyes, A. (2010). El derecho a la Ciudad. Praxis de la utopía. Hábitat y Sociedad, 1.

Tejedor Bielsa, J. (2010). Las viviendas protegidas. Régimen jurídico general de la vivienda protegida. En V.AA., López Ramón, F. (coord.), Construyendo el derecho a la vivienda. Madrid: Marcial Pons.

Tribillon, J.F. (2003). Le droit à la ville. París, Association Internationale de Techniciens, Experts et Chercheurs.

Villalibre Fernández, V. (2011). El derecho a una vivienda adecuada. Un derecho del siglo XxI. Estudios de Progreso, Fundación Alternativas, 64.

VV.AA., Nasarre, S. (dir), Simón, H. (coord.) (2011). El acceso a la vivienda en un contexto de crisis. Madrid: Edisofer.

V.AA., López Ramón, F. (coord.) (2010). Construyendo el derecho a la vivienda. Madrid: Marcial Pons.

V.AA., Ponce, J. y Sibina, S. (coords.) (2008). El derecho a la vivienda en el siglo XXI: sus relaciones con la ordenación del territorio y el urbanismo. Madrid: Marcial Pons. 
Galiana Saura, A. (2017). La vivienda como objeto de estudio desde el derecho: la vivienda como derecho humano y la cátedra UNESCO sobre vivienda. Hábitat y Sociedad, 10, 129-144.

<http://dx.doi.org/10.12795/HabitatySociedad.2017.i10.08>

$\bigcirc$ 